\title{
An overview of the synergy and crosstalk between pentraxins and collectins/ficolins: their functional relevance in complement activation
}

\author{
Ying Jie $\mathrm{Ma}^{1}$, Bok Luel Lee ${ }^{2}$ and Peter Garred ${ }^{1}$ \\ The complement system is an innate immune defense machinery comprising components that deploy rapid immune responses \\ and provide efficient protection against foreign invaders and unwanted host elements. The complement system is activated upon \\ recognition of pathogenic microorganisms or altered self-cells by exclusive pattern recognition molecules (PRMs), such as \\ collectins, ficolins and pentraxins. Recent accumulating evidence shows that the different classes of effector PRMs build up a \\ co-operative network and exert synergistic effects on complement activation. In this review, we describe our updated view of the \\ crosstalk between previously unlinked PRMs in complement activation and the potential pathogenic effects during infection and \\ inflammation.
}

Experimental \& Molecular Medicine (2017) 49, e320; doi:10.1038/emm.2017.51; published online 21 April 2017

\section{INTRODUCTION}

The complement system is an important part of humoral and cellular innate immunity that mobilizes immune defense mediators to handle microbes and endogenous waste materials. ${ }^{1,2}$ The complement system consists of the following three activation pathways: the classical pathway $(\mathrm{CP})$, lectin pathway (LP) and alternative pathway (AP). The CP is mainly activated by $\mathrm{C} 1 \mathrm{q}$ and associated serine proteases upon binding to antibodies. ${ }^{3}$ The LP activation is primarily induced by collagen-like humoral pattern recognition molecules (PRMs), such as mannose-binding lectin (MBL), the ficolins, collectin10 (CL-10 or CL-L1), collectin-11 (CL-11 or CL-K1) or a heteromeric complex of CL-10 and CL-11 (CL-LK). ${ }^{4-8}$ In contrast, the AP does not require antibodies or soluble PRMs for its initiation and is often referred to as spontaneous and indiscriminate because it does not differentiate between self and non-self. Rather, initiation of the AP occurs by spontaneous low-rate hydrolysis of the thioester in C3, which is quickly amplified if an additional starting signal is provided by the CP and LP (Figure 1). ${ }^{9}$ Thus, in many instances, the AP may be regarded as an amplification loop.

Humoral PRMs and the complement system are indispensable immune defense factors and are the first line of defense against danger signals. However, the roles of humoral PRMs have been fairly oversimplified in the separate pathways of the complement system (Figure 1). Recently, the crosstalk between different classes of humoral PRMs and its involvement in complement cross-activation has been highlighted. ${ }^{8}$ In this review, we provide an overview of the key humoral PRMs and their potential co-operative interactions during complement activation and amplification, and discuss the potential aspects of both beneficial and deleterious effects in physiological and pathological situations.

COLLECTINS, FICOLINS AND PENTRAXINS: ESSENTIAL COMPONENTS FOR COMPLEMENT-MEDIATED IMMUNE RESPONSES

Collectins are members of the C-type lectin superfamily that recognize sugar moieties exposed on pathogens and facilitate opsonophagocytosis. ${ }^{10}$ All collectins possess two structural characteristics, a collagen-like domain and a carbohydraterecognition domain. ${ }^{11,12}$ In a conceptual manner, collectins can be categorized as either classical or novel collectins, which consist of MBL/surfactant protein-A/surfactant protein-D and CL-10/CL-11/CL-12, respectively. ${ }^{13}$

\footnotetext{
${ }^{1}$ The Laboratory of Molecular Medicine, Department of Clinical Immunology, Section 7631, Rigshospitalet, Faculty of Health and Medical Sciences, University of Copenhagen, Copenhagen, Denmark and ${ }^{2}$ National Research Laboratory of Defense Proteins, College of Pharmacy, Pusan National University, Busan, Korea

Correspondence: Dr YJ Ma, The Laboratory of Molecular Medicine, Department of Clinical Immunology, Sect 7631, Rigshospitalet, University of Copenhagen, Copenhagen 2200, Denmark.

E-mail: ying.jie.ma@regionh.dk

Received 30 November 2016; accepted 30 December 2016
} 


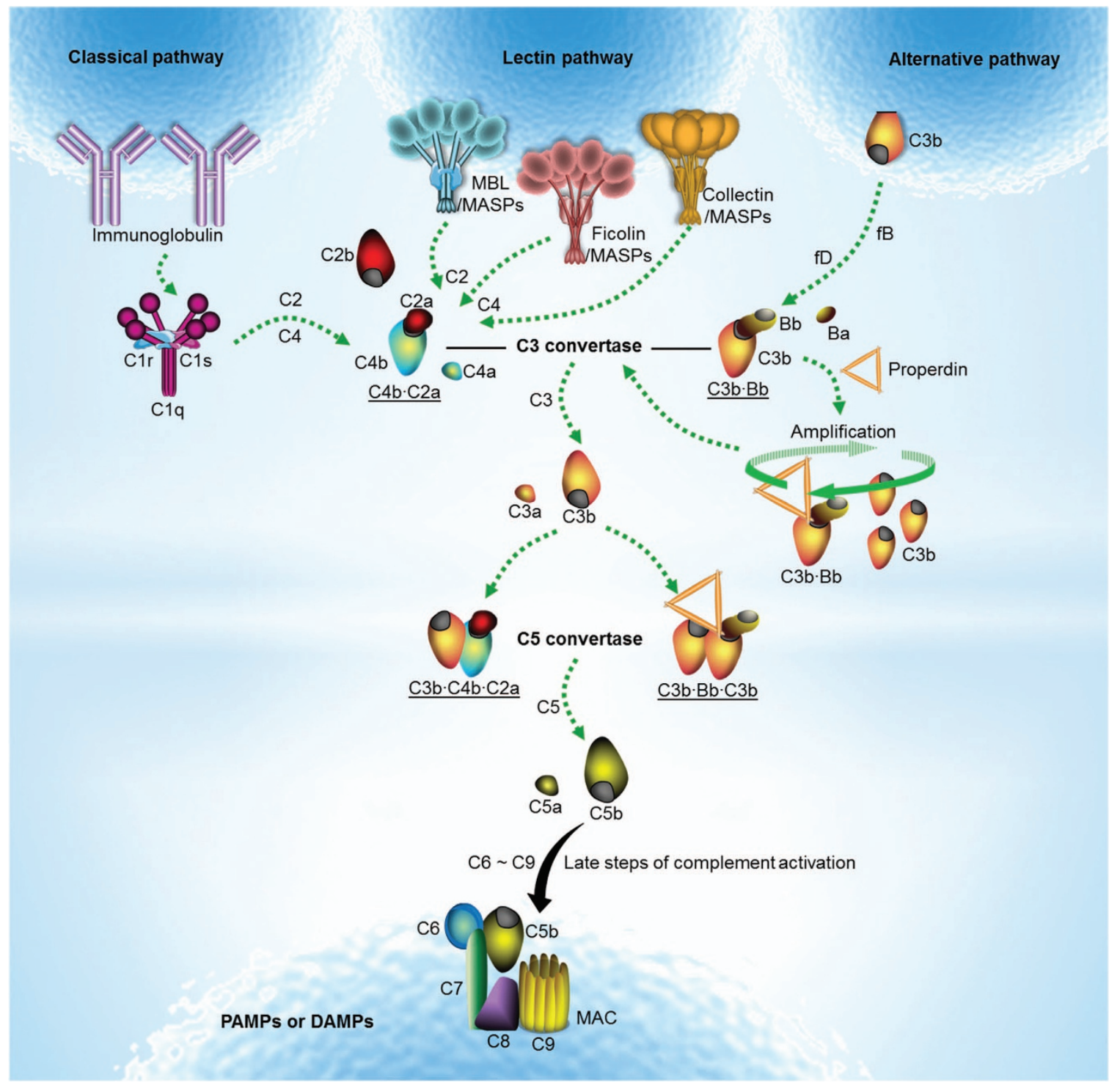

Figure 1 General view of complement activation. The complement system comprises the following three activation pathways: the classical, lectin and alternative pathways. The classical pathway is activated when the C1 complex (the molar ratio of $\mathrm{C} 1 \mathrm{q}, \mathrm{C} 1 \mathrm{r}$ and $\mathrm{C} 1 \mathrm{~s}, 1: 2: 2$ ) binds immunoglobulins (mainly lgG clusters) that recognize pathogen-associated molecular patterns (PAMPs) or damage-associated molecular patterns (DAMPs). Activation of the lectin pathway is induced by PRMs, such as mannose-binding lectin, ficolins (ficolin-1, -2 or -3 ) or collectins (collectin-10 or collectin-11), upon binding to PAMPs or DAMPs. The lectin pathway-initiating PRMs are found in complexes with LP-associated serine proteases (MASPs), whereas $\mathrm{C} 1 \mathrm{q}$ is found in complexes with the serine proteases $\mathrm{C} 1 \mathrm{r}$ and $\mathrm{C} 1 \mathrm{~s}$. Activation of the classical and lectin pathways leads to cleavage of $\mathrm{C} 4$ and $\mathrm{C} 2$, and the formation of a $\mathrm{C} 3 \mathrm{convertase}(\mathrm{C} 4 \mathrm{~b} \cdot \mathrm{C} 2 \mathrm{a})$. Initiation of the alternative pathway occurs by spontaneous hydrolysis of C3 in solution. Activated C3 leads to formation of the initial C3b, which covalently bind to target surfaces. Surface-bound C3b allows factor $B(f B)$ to bind. $f B$ is then cleaved by the enzyme factor $D(f D)$, leading to the formation of the alternative $\mathrm{C} 3$ convertase $(\mathrm{C} 3 \mathrm{~b} \cdot \mathrm{Bb})$. The alternative $\mathrm{C} 3$ convertase is stabilized by the plasma protein properdin. The C3 convertases cleave C3 into the opsonin C3b and the anaphylatoxin C3a. Activation of C3 also leads to the formation of the

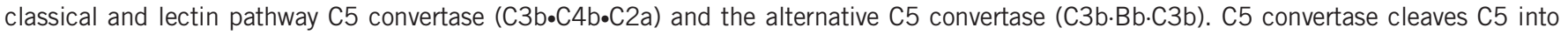
the anaphylatoxins $\mathrm{C} 5 \mathrm{a}$ and $\mathrm{C5b}$. Deposition of C5b onto a target initiates formation of the membrane attack complex (C5b-9, MAC) in the late steps and leads to lysis of the target. The alternative pathway also works as an amplification loop for the classical and lectin pathways.

Among the different types of collectins, MBL/CL-10/CL-11 have been shown to be involved in LP complement activation and regulation via association with the LP-associated serine proteases (MASPs) and two non-enzymatic proteins named small MBL-associated protein (sMAP) (MAp19) and MBL/ Ficolin-associated protein-1 (MAP-1) (MAp44). ${ }^{14}$ In contrast, surfactant protein-A and surfactant protein-D are mainly distributed throughout the airways and play a homeostatic role in the regulation of lung surfactant but also function as pulmonary opsonins to sequester pathogens by employing a variety of mechanisms other than complement activation. ${ }^{15,16}$ Different from the other novel collectins, CL-12 was originally defined as a scavenger receptor C-type lectin, because it shares structural and functional similarities with the type A scavenger 
receptor and collectins. ${ }^{17,18}$ As a transmembrane scavenger receptor, CL-12, is mainly localized in vascular endothelial cells $^{19}$ and revealed pattern recognition characteristics in response to Sacharomyces, as well as E. coli and $S$. aureus. ${ }^{18,19}$ Recently, soluble CL-12 has also been detected and shown to induce AP activation. ${ }^{20}$

Ficolins are a class of collagenous defense proteins containing collagen-like domains and fibrinogen-like domains (FDs). ${ }^{21,22}$ The three members of the ficolin family include ficolin-1 (M-ficolin), ficolin-2 (L-ficolin) and ficolin-3 (H-ficolin or Hakata antigen). Ficolin-2 is mainly produced in the liver, whereas Ficolin-3 is synthesized in both the liver and lungs. Ficolin-2 and Ficolin-3 circulate in the blood with a median concentration of 5 and $25 \mu \mathrm{g} \mathrm{ml}^{-1}$, respectively. ${ }^{23,24}$ Ficolin-1 is primarily expressed by cell types of myeloid origin and is present in the blood at a relatively low level $\left(\sim 0.3 \mu \mathrm{g} \mathrm{ml}^{-1}\right) .{ }^{25-27}$ Functionally, the ficolins recognize a wide spectrum of different types of microorganisms via their FD and have potentials to activate the LP to a different extent in complex with LP-associated serine proteases via collagen-like domain. $^{28,29}$

Pentraxins are a superfamily of soluble PRMs characterized by a cyclic multimeric structure. ${ }^{30}$ On the basis of the primary structure of the subunit, the pentraxins are defined as short pentraxins or long pentraxins. C-reactive protein (CRP or pentraxin 1 (PTX1)) and serum amyloid P component (SAP or PTX2) are the classical short pentraxins, whereas PTX3 was the first identified long pentraxin. Both CRP and SAP are produced by hepatocytes in response to inflammatory cytokine stimulation and are the major acute phage reactants in human and mouse, respectively. Unlike the short pentraxins, PTX3 is expressed by a variety of cell types of extrahepatic origin, such as macrophages, neutrophils, dendritic cells and endothelial cells. Under normal conditions, PTX3 is hardly detectable in human serum $\left(<2 \mathrm{ng} \mathrm{ml}^{-1}\right)$, whereas its synthesis is rapidly $(6-8 \mathrm{~h})$ and markedly $\left(200-800 \mu \mathrm{gl}^{-1}\right)$ upregulated in response to inflammatory and infectious stimuli. ${ }^{31}$ The pentraxins share structural similarity with the C-terminal pentraxin domain, whereas PTX3 contains a unique N-terminal region, which has no sequence homology to any known proteins so far. ${ }^{31}$ The pentraxins recognize different classes of molecular patterns present on microorganisms, but also recognize endogenous extracellular matrix proteins as well as structures exposed on dying host cells. ${ }^{32}$ As a common functional feature, the pentraxins interact with adaptive $\mathrm{Fc \gamma}$ receptors on hematopoietic cells upon target opsonization and increase phagocytosis and acute inflammation. Furthermore, their interactions with $\mathrm{Clq}$ also increase complement activation. ${ }^{33-35}$

\section{SYNERGY BETWEEN PREVIOUSLY UNLINKED PRMS IN PATTERN RECOGNITION AND COMPLEMENT ACTIVATION}

\section{A hidden innate immune connection conserved from arthropods to mammals}

The biological functions of the complement system have been shown to be elicited as a result of activation by three separate and autonomous routes, of which the $\mathrm{CP}$ and LP require distinctive soluble PRMs for complement activation on target surfaces. In addition to the antibody (IgM or IgG cluster)dependent 'classical' activation, recent data have shown that the $\mathrm{CP}$ is also initiated by $\mathrm{C} 1 \mathrm{q}$ in conjunction with endogenous pentraxins, such as CRP, SAP and PTX3. ${ }^{33,36,37}$ Antibodies are secreted by B-cells that often undergo a lengthy stage of differentiation and proliferation upon antigen stimulation and are highly specific to certain antigens. In contrast, pentraxins are swiftly and markedly activated at both systemic and local tissue levels in response to microbial sensing and inflammatory cytokines and broadly recognize wide spectrum of different pattern moieties. Thus, pentraxin-mediated complement activation is much more rapid and efficient at the early stage of infection than antibodies, providing immediate humoral and cellular immune responses against danger signals. $^{32}$ Evolutionally, pentraxins together with complement components, such as $\mathrm{Clq}$, are both ancient immune elements and highly conserved in species ranging from mammals, vertebrates and lizards to horseshoe crabs. ${ }^{38,39}$ Antibodies, particularly IgGs, are relatively recent evolutionary immune mediators and are highly diverse among various species but highly conserved in mammalian species. In this context, it should be emphasized that the pentraxins possess antibody-like functions, not only in the context of C1q-mediated complement activation, but also in a variety of humoral and cellular immune effector functions, such as phagocytosis, endocytosis, inflammatory cytokine expression and antibody-independent cellular cytotoxicity.

Nevertheless, the role of the short pentraxin CRP has been rather controversial between both in vitro and in vivo findings of its ability to assist in protection against certain pathogens, especially toward Streptococcus pneumoniae and Salmonella enterica. It has remained elusive because of the following reasons. (1) The level of human CRP is highly elevated during bacterial infection. ${ }^{40}$ Mice administered human CRP or human CRP-transgenic mice that were infected with S. pneumoniae (or S. enterica) had reduced bacteremia and increased survival compared with controls. ${ }^{41-43}$ (2) In contrast, in vitro evaluation did not reveal direct binding of purified CRP to most bacteria including $S$. enterica, ${ }^{43,44}$ and CRP did not activate the CP of complement in $S$. pneumoniae-infected mice. ${ }^{45}$ Finally, CRP is not a major acute-phase protein in mice. ${ }^{46}$ Explanations for these apparent contradictions in the in vivo role of CRP in resistance to infection comes from studies in arthropod models, such as the horseshoe crab, which relies entirely on innate immune mechanisms and naturally induced defenses via evolutionally conserved molecules such as CRP, which is an important PRM in the hemolymph (horseshoe crab blood). ${ }^{47,48}$ Interestingly, these studies revealed apparent differences in CRP in isolation and in the complex hemolymph. CRP recognizes a wider range of bacteria in the presence of hemolymph than when tested in isolation, and the enhanced binding of CRP and its remarkable bactericidal ability are elicited by collaboration with certain innate PRMs in the hemolymph, such as horseshoe crab (Tachypleus spp.) lectin and carcinolectin-5 (CL-5). ${ }^{49}$ 
Previously, Ma and Lee et al. identified peptidoglycan recognition proteins (PGRPs, and 1,3- $\beta$-D-glucan recognition proteins (BGRPs) from insect hemolymph and characterized its crucial role in the activation of the prophenoloxidase (proPO) system (a major humoral defense reaction in arthropods). ${ }^{50}$ Several lines of evidence revealed that the arthropod proPO system shares some similarities with the mammalian LP of the complement system. ${ }^{51,52}$ Both the proPO system and the LP of the complement system are proteolytic cascades comprising various PRMs for recognition, serine proteases for response and their inhibitors for regulation and terminators for resolution. ${ }^{53}$ Moreover, the genes encoding PGRPs are highly conserved in the sequences between insects and mammalian species. ${ }^{54-57}$ Interestingly, in an attempt to further characterize the human counterparts of these molecules and their functional consequences, Ma and Lee et al. purified a PGRP and BGRP from human serum and identified complement-related proteins, specifically MBL and ficolin-2. A previous study revealed that human PGRP and BGRP could also function as soluble PRMs for peptidoglycan and 1,3- $\beta$-D-glucan, respectively. ${ }^{50}$ Altogether, these results have provided insights into the hidden nature of an innate immune connection that may be highly conserved from arthropods to mammals.

Ficolin:pentraxin heterocomplexes in complement activation Many PRMs are evolutionally conserved from horseshoe crab to human, indicating that these proteins are essential in innate immunity. ${ }^{58,59}$ The human ficolins (ficolin-1, -2 and -3) have been revealed to share $\sim 35 \%$ homology with horseshoe crab tachylectin-5s and CL-5s, which both harbor an FD. ${ }^{60,61}$ On the basis of the studies in arthropods, Patricia et al. have recently highlighted that such conserved innate PRMs have the ability to build up potential crosstalk to synergize innate immune defenses and found that CRP interacts with the ficolins in human. ${ }^{49}$

Human CRP has been reported to interact with ficolin-2 (CL-5 homolog), thus allowing CRP to effectively recognize and stabilize its anchorage onto certain bacteria that it does not naturally recognize. This collaboration has been shown to specifically enhance the recognition of $S$. enterica and activate the LP of complement on the surface of this pathogen. Previous research suggested that CRP may organize mutual coordination with other PRMs to target a wide range of bacteria and adapt to diverse pathogenic circumstances. ${ }^{49}$ This hypothesis has been recently substantiated by several lines of evidence from clinically important opportunistic pathogens that have become major causes of mortality in immunecompromised patients, such as Pseudomonas aeruginosa, ${ }^{62}$ Aspergillus fumigatus ${ }^{63}$ and Candida albicans. ${ }^{64}$ In one study, the ficolin-2:CRP interaction prevails under local infectioninflammation conditions with reduced $\mathrm{pH}$ and calcium levels, which are common phenomenon in many inflammatory infection-related diseases, such as acidosis, trauma-induced infection, acute renal failure and intra-abdominal infection. Interestingly, this interaction has been demonstrated to induce powerful complement-mediated anti-microbial activity via cross-activation of the CP and LP, which were previously defined as independent of each other. ${ }^{62}$

PTX3 originated very early and even ascended to amphibians, such as Xenopus laevis, and it is highly conserved evolutionally. The PTX3 structure possesses a C-terminal pentraxin domain coupled with a unique N-terminal region, which has endowed PTX3 with different effector functions than the short pentraxins, such as recognition of fungal pathogens, ${ }^{65}$ complement regulation, ${ }^{66-68}$ extracellular matrix deposition/ angiogenesis ${ }^{69,70}$ and tissue repair. ${ }^{71}$ In an attempt to better understand the ligand specificity of ficolins toward fungal pathogens, we found that ficolin-2 preferentially recognizes $1,3-\beta$-D-glucan moiety in addition to the $N$-acetyl-glucosamine moiety on $A$. fumigatus through its $\mathrm{FD}$ and subsequently activates the LP of complement in association with LP-associated serine protease-2. Interestingly, we also confirmed that serum ficolin-2 can interact with PTX3 and demonstrated that ficolin-2 and PTX3 recruit each other in response to an opportunistic fungal pathogen, A. fumigatus. Functionally, this ficolin-2:PTX3 interaction leads to reciprocal communication between the CP and LP, and eventually results in boosting complement-mediated anti-fungal activity via expansion of pattern recognition and complement amplification. $^{63}$ In agreement with our findings, a recent shotgun proteomics analysis of the PTX3 complexes in patients with sepsis also substantiated the presence and importance of complement components including ficolin-2 in crosstalk with PTX3. ${ }^{72}$

Aspergillus species are ubiquitous saprophytic molds that cause devastating invasive fungal infections (invasive aspergillosis) associated with a high mortality rate in immunocompromised hosts. Among the human pathogenic species, the most common causative agent of human infections is A. fumigatus. ${ }^{73}$ The non-redundant role of the complement system in resistance to invasive aspergillosis has been well documented in DBA/2N mouse models. ${ }^{74}$ Recently, in an immunocompromised host, the LP was shown to be crucial for complement initiation on A. fumigatus. ${ }^{75}$ Complement deficiency increases susceptibility to A. fumigatus infection and increased mortality rates have been observed in C5-knockout mice. $^{76,77} \mathrm{We}$ and others have recently highlighted the significance of ficolin-2-mediated anti-fungal activity in the LP of complement activation or modulation of both proand anti-inflammatory airway immune responses against A. fumigatus challenge. ${ }^{63,78,79}$ Both ficolin-2 and ficolin-A (ficolin-2 homolog in mice) have been shown to recognize A. fumigatus, and it was recently shown that ficolin knockout mice have increased fungal load compared with wild-type mice. ${ }^{80}$ However, only ficolin-2 is capable of inducing the LP of complement activation upon opsonization. In contrast, ficolin-A has been shown to enhance adherence of the fungus to A549 airway epithelial cells and modulate inflammation via production of pro-inflammatory cytokines. ${ }^{78}$ Furthermore, ficolin-A has also been shown to inhibit hyphae growth and increase fungal killing by monocyte-derived macrophages and neutrophils. $^{79}$ Nevertheless, consistent with the previous 
structural determination of $\mathrm{FD}$, both of the ficolins are insensitive to $\mathrm{Ca}^{2+}$ but rather sensitive to an acidic environment ( $\mathrm{pH}$ 5.7), ${ }^{81,82}$ which is common at the site of local infection and often drops to as low as $\mathrm{pH} 5.5$ during inflammation. ${ }^{83}$ This finding is very consistent with the observation of a pH-sensitive CRP:ficolin-2 interaction reported by Zhang et al. ${ }^{62}$ These data suggest that infectioninduced local acidic conditions may be essential to optimize ficolin opsonization at the early stage of infection and inflammation against $A$. fumigatus. In agreement with those in vitro findings, ficolin-2 was also found in bronchoalveolar lavage fluids from the lungs of patients with invasive aspergillosis. Alveolar ficolin-2 has also been demonstrated to potentially modulate immune responses to $A$. fumigatus. These results suggest that liver-expressed ficolin-2 may translocate to the alveoli from the bloodstream. ${ }^{82}$ Therefore, in this respect, it should be emphasized that migratory serum ficolin-2 may boost complement-mediated opsonophagocytosis and modulate the anti-inflammatory cytokine profile at local sites of pulmonary fungal infection. Furthermore, collaboration of ficolin-2 with locally produced PTX 3 may also provoke a synergistic effect on complement-mediated immune responses.

An animal study has previously demonstrated that PTX3 plays a non-redundant role in resistance to opportunistic fungal pathogens, A. fumigatus in particular. In vivo data showed that $p t \times 3^{-1-}$ mice are highly susceptible to invasive pulmonary aspergillosis, but this phenotypic defect can be reversed by administration of recombinant PTX3, which has been attributed to defective recognition of $A$. fumigatus conidia by alveolar macrophages and dendritic cells. ${ }^{65,84}$ Consistently, an in vitro study has shown that PTX3 enhances phagocytic engulfment of conidia by neutrophils via FcyRII. ${ }^{85}$ In addition, PTX3-opsonized $A$. fumigatus has been shown to activate the $\mathrm{CP}$ of complement through association of $\mathrm{Clq}^{85}$ and crossactivate the LP of complement through an interaction with ficolin-2. ${ }^{63}$ In agreement with these findings, a singlenucleotide polymorphism in PTX3 in homozygous haplotype donor individuals was shown to be linked to an increased risk of invasive aspergillosis in stem cell recipients of such donor cells. ${ }^{86}$ These data suggest that PTX3 may play crucial roles in resistance to invasive pulmonary aspergillosis.

Altogether, ficolin-2 and PTX3 play non-redundant roles in resistance to invasive pulmonary aspergillosis. The crosstalk between ficolin-2 and PTX3 is likely to provide a platform for cross-activation of immune effector mechanisms, leading to a synergistic effect at local sites of pulmonary infection/ inflammation. Ficolin-1, the only ficolin isoform expressed by immune cells, ${ }^{26,27,87}$ has also been shown to interact with CRP and PTX3. ${ }^{88-90}$ Zhang et al. reported that ficolin-1 interacts with $\mathrm{CRP}$ in a $\mathrm{pH}$-sensitive manner, whereby ficolin-1 switches structural conformation between its inactive and active form during contact with CRP. Functionally, ficolin-1 has been shown to regulate interleukin-8 production both pre-infection and post-infection through transduction of infection signals by G-protein-coupled receptor 43 at the local site of infection/inflammation. These results suggest that
ficolin-1:CRP interaction functions as an immune recognitionregulation circuit to prevent immune overactivation in a $\mathrm{pH}$-sensitive manner by recruitment of certain transmembrane receptors on immune cells. ${ }^{89}$ In agreement with these findings, we have found that the ficolin-1:PTX3 interaction may behave in a manner similar to that of the ficolin-1:CRP interaction upon variations in $\mathrm{pH}$. We have demonstrated that PTX3 recognizes dying host cells, but it requires ficolin-1 to mediate removal of the cells. Moreover, the complex formation between ficolin-1 and PTX3 downregulates the release of interleukin- $8 .^{90}$ These findings imply that heterocomplexes and collaborative interactions between autonomous collagenlike defense molecules and pentraxins appear to lead to novel reciprocal trends of immune surveillance and effector mechanisms that aid in the safe disposal of dying host cells, whereby excessive inflammatory responses and tissue injury may effectively be prevented.

\section{MBL:pentraxin heterocomplexes in complement activation}

Pentraxins recognize a number of microorganisms, including bacteria, fungi and viruses, ${ }^{91}$ but do not bind C. albicans and Burkholderia cepacia. ${ }^{65}$ In an unexpected twist, we have observed that incubation of human serum with $C$. albicans resulted in binding of pentraxins (PTX3 and SAP in particular, but not CRP) to C. albicans. This observation implies that some serum factors might enhance the docking of pentraxins on this fungal pathogen, which has not been shown to be solely recognized by pentraxins. We found that PTX3 or SAP do not surveil alone but interact with other serum PRM to achieve stable immune recognition complexes on certain fungal pathogens. We also revealed that serum MBL contributes to the recruitment of PTX3 or SAP on C. albicans upon binding. MBL:PTX3 complex formation resulted in recruitment of C1q, but this was not observed for MBL:SAP complexes. However, both MBL:PTX3 and MBL:SAP complexes enhanced complement-mediated opsonophagocytosis of $C$. albicans by polymorphonuclear leukocytes. ${ }^{64}$ These findings suggest that fungal infection might induce potential crosstalk between previously unlinked serum PRMs for immune defense, which provide two potential complement amplification mechanisms. One mechanism consists of complexes comprising MBL, PTX3 and $\mathrm{C} 1 \mathrm{q}$, which amplify complement activation via the $\mathrm{CP}$, and the other involves MBL and SAP, which amplify complement activation via an unknown mechanism.

\section{CL-12:properdin crosstalk in complement activation}

Decades of research have solidified the role of properdin as a stabilizer of the AP C3 convertase $\mathrm{C} 3 \mathrm{bBb}$, but the properdin protein was attributed a relatively nonspecific role. ${ }^{92}$ Previously, properdin has been shown to bind AP activator surfaces strictly in a C3-dependent manner. ${ }^{93,94}$ However, several lines of recent evidence also suggest that properdin alone may provide a platform for the in situ assembly of the $\mathrm{C} 3 \mathrm{bBb}$ complex on target surfaces. ${ }^{95,96}$ Recently, we found that membrane-anchored CL-12 might be cleaved in close vicinity to the plasma membrane at its $\mathrm{N}$ terminus and circulate in 
Table 1 Crosstalk of soluble PRMs involved in pattern recognition and complement activation

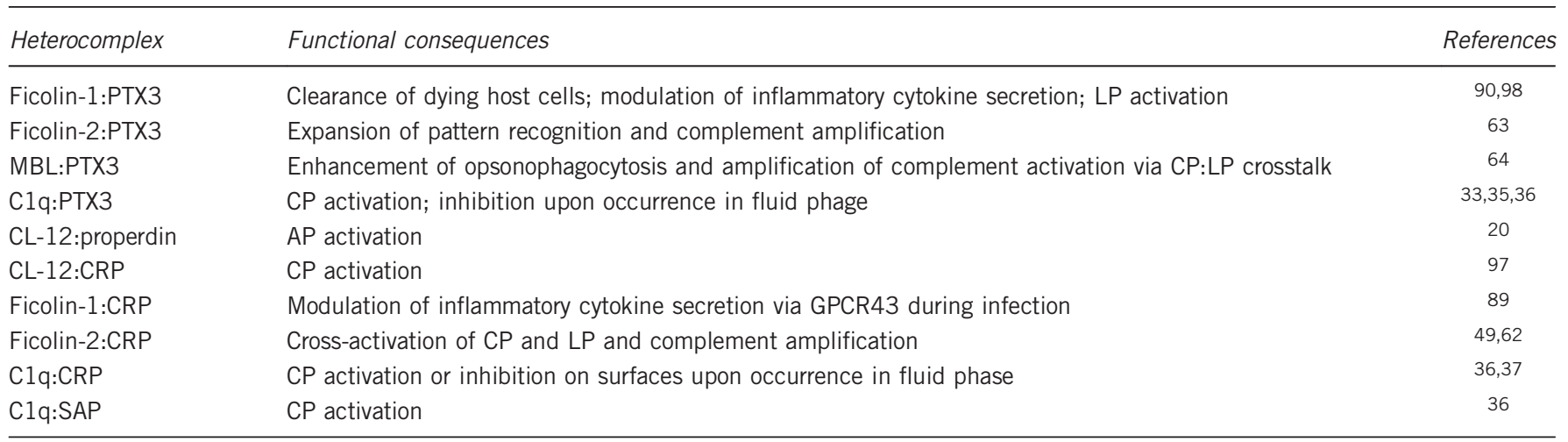

Abbreviations: AP, alternative pathway; CP, classical pathway; CRP, C-reactive protein; GPCR43, G-protein-coupled receptor 43; LP, lectin pathway; PTX, pentraxin; SAP, serum amyloid P component.

normal human umbilical cord plasma at 55-121.4 $\mathrm{ng} \mathrm{ml}^{-1}$. Furthermore, we have demonstrated that soluble CL-12 recruits properdin to target surfaces, thereby allowing AP activation. ${ }^{20}$ Taken together, our results revealed that given a platform via a co-operative immune response integrating signals from another 'sensory' input, for instance soluble PRM, properdin is able to mediate de novo C3 convertase assembly and initiate complement activation on certain pathogens via recognition of specific target surfaces by its 'sensory' input. In this respect, this 'sensory' input manner seems to be rather selective and specific, compared with the standard manner of the AP of complement activation via a highly reactive but non-discriminating nascent $\mathrm{C} 3 \mathrm{~b}$. Therefore, we envision that properdin plays a role in the AP of complement activation not only by stabilizing preformed $\mathrm{C} 3 \mathrm{bBb}$ but also by providing a platform for de novo $\mathrm{C} 3$ convertase assembly once surface-bound through co-operative recognition by the humoral innate immune system. However, both mechanisms probably require generation of nascent $\mathrm{C} 3 \mathrm{~b}$ for initiation.

Nevertheless, in support of our notion that different PRMs might collaborate to provide a platform for construction of multiple defense barriers via complement activation and amplification, Nitai et al. ${ }^{97}$ recently reported crosstalk of transmembrane CL-12 with the short pentraxin CRP in a charge-dependent manner, whereby CL-12 triggers the CRP-mediated CP of complement activation and propels the subsequent amplification loop of complement through properdin deposition. Consistent with our findings, these results suggest that transmembrane CL-12 might not act alone in properdin-driven complement amplification. However, upon collaboration with other serum factors or immune mediators, such as CRP, CL-12 seems to be either active or deleterious due to complement crosstalk, which may trigger and exacerbate pathological conditions.

Taken together, as the CP and LP of complement rely upon soluble PRMs for initiation, the AP of complement may also be initiated by specific recognition molecules via collaboration with properdin. This soluble CL-12:properdin (or CRP) collaboration and its involvement in complement activation could be particularly effective against certain clinically relevant pathogens, such as A. fumigatus, and may also be a complementary countermeasure to manipulate the crafty immune evasion tactics that have been increasingly evolving in pathogens.

\section{PROTECTIVE VS PATHOGENIC EFFECTS OF CO-OPERATIVE INTERACTIONS OF PRMS}

As depicted above, many PRMs are evolutionally conserved, and their potential crosstalk recently has been unveiled (Table 1). To rapidly and efficiently defend against multiple danger signals, many PRMs likely collaborate and deploy a variety of immune effector functions, leading to synergistic effects in immune recognition, response and resolution. These co-operative immune events are likely to widen the repertoire of pattern recognition and diversify immune effector functions to cope with the evolving immune evasion tactics of pathogens (Figure 2).

Despite the obvious evidence accumulating for the crucial protective roles of such immune events during microbial invasion, several lines of evidence suggest that PTX3, MBL and those collaborations also appear to mediate pathogenic effects during microbial infections. ${ }^{99-101}$ The evidence supports a potential deleterious effect on immunopathogenicity because of the following observations. (1) PTX3-overexpressing transgenic murine models that were infected with a high inoculum of Klebsiella pneumoniae exhibited accelerated lethality, which has been attributed to decreased neutrophil infiltration into the lung tissues and increased dissemination of bacteria in the blood during acute infection. ${ }^{99}$ (2) In ross river virus (RRV)-infected mice, the MBL-mediated LP of complement activation was shown to exacerbate alphavirus-induced arthritis during acute RRV infection. Importantly, a significant correlation has been observed between the MBL levels in serum and synovial fluid, and the severity of disease in RRV-infected individuals. $^{100}$ (3) The overt expression of PTX3 has been shown to promote early viral entry and viral replication during the acute phase of alphavirus infection through modulating recruitment of monocyte-differentiated DC and macrophages as well as pro-inflammatory cytokines, such as tumor necrosis factor- $\alpha$, interleukin- 6 and interferon- $\gamma .{ }^{101}$ (4) MBL:PTX3 


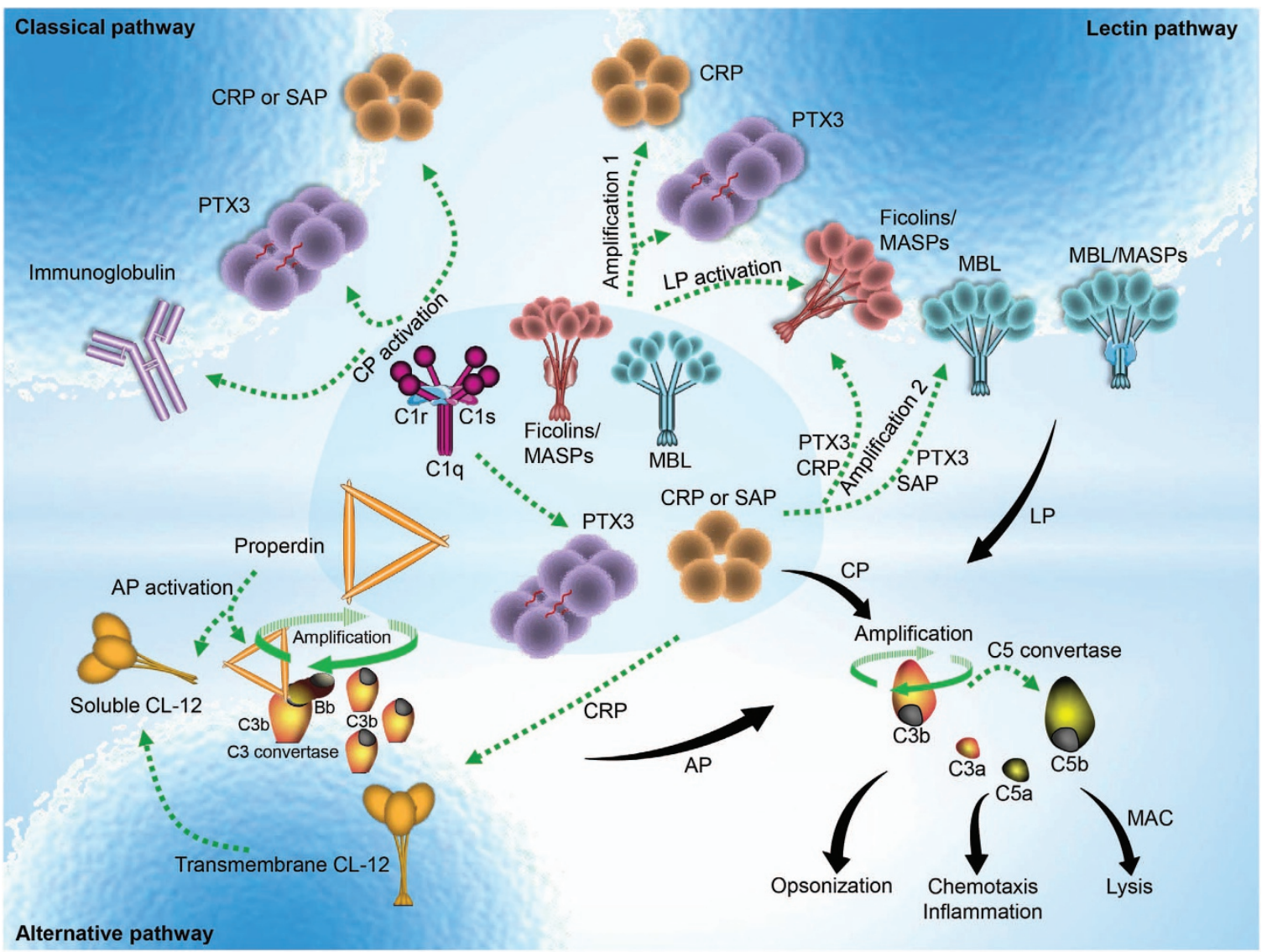

Figure 2 An expanded network of complement activation by previously unlinked PRMs. The model reevaluates the classical view of complement activation that is mediated exclusively via complement PRMs and highlights the synergistic effects of complement PRMs on complement-mediated immune responses. The classical pathway (CP) is mainly activated in an antibody-dependent manner by lgG clusters (or IgM) but is also initiated through pentraxins, such as PTX3, C-reactive protein (CRP) and serum amyloid P component (SAP), via C1q. In addition, surface-bound collectin-12 (CL-12) is hypothesized to mediate CP activation by crosstalk with CRP. Activation of the lectin pathway (LP) is induced directly by mannose-binding lectin (MBL), ficolins and collectins but can also be mediated by $\mathrm{MBL}$ or ficolins through PTX3, CRP or SAP. Moreover, the CP and LP are capable of being cross-activated through formation of heterocomplexes between PTX3 (or CRP) and MBL (or ficolin-2) and C1q. The cross-activation comprises two amplification pathways: target $\rightarrow$ PTX3 (or $\mathrm{CRP}$ ) $\rightarrow$ ficolin-2/MASPs $\rightarrow \mathrm{C} 4 \rightarrow \mathrm{C} 3 \rightarrow$ formation of the membrane attack complex (MAC; amplification 1); target $\rightarrow \mathrm{MBL}$ (or ficolin-2/ MASPs) $\rightarrow$ PTX3 (or CRP) $\rightarrow \mathrm{C} 1 \mathrm{q} \rightarrow \mathrm{C} 4 \rightarrow \mathrm{C} 3 \rightarrow$ formation of MAC (amplification 2). Initiation of the alternative pathway (AP) occurs by spontaneous low-rate hydrolysis of the thioester in C3 and quickly spreads to nearby surfaces via nascent C3b, which binds covalently to a target. As an additional activation route, it has been suggested that soluble CL-12 in collaboration with properdin provides a platform for de novo C3 convertase assembly. All activation pathways consequently lead to opsonization, chemotaxis, inflammation and lysis against microbes or dying host cells.

heterocomplex-mediated opsonophagocytosis and complement amplification may further exacerbate disease severity during alphavirus infection. ${ }^{102}$

\section{CONCLUDING REMARKS}

The co-operative immune events between the collagen-like defense molecules and pentraxins have been increasingly acknowledged for their roles in immunosurveillance and host immune defense against microbial invasion. However, the growing list of evidence suggests immunopathogenicity of those co-operative events in the progression of arthritis induced by alphavirus infection, such as chikungunya virus and RRV infection, and also emphasizes the potential deleterious impact on pathogen immune evasion and development of complement-related diseases. The pathogenic side of the potential functional roles of MBL, PTX3 and their involvement in complement activation needs to be further explored: whether the MBL:PTX3 complex is involved in alphavirusinduced arthritis during the acute phase of infection and how it exacerbates disease severity are both intriguing unanswered questions. Accordingly, those immune heterocomplexes may also be crucial drug targets for the development of complement-immune therapies against the consequences of certain viral infections, such as alphavirus infection and possibly complement-related diseases in general.

\section{CONFLICT OF INTEREST}

The authors declare no conflict of interest. 


\section{ACKNOWLEDGEMENTS}

This work was supported by grants from the Kirsten og Freddy Johansens Fond, the Weimann and Seedorffs Foundation, the Benzon Foundation, the Research Foundation of the Capital Regions of Denmark, the Novo Nordisk Research Foundation, The Danish Research Foundation of Independent Research and the Svend Andersen Research Foundation.

1 Ricklin D, Hajishengallis G, Yang K, Lambris JD. Complement: a key system for immune surveillance and homeostasis. Nat Immunol 2010; 11: 785-797.

2 Kolev M, Le Friec G, Kemper C. Complement-tapping into new sites and effector systems. Nat Rev Immunol 2014; 14: 811-820.

3 Gaboriaud C, Thielens NM, Gregory LA, Rossi V, Fontecilla-Camps JC, Arlaud GJ. Structure and activation of the C1 complex of complement: unraveling the puzzle. Trends Immunol 2004; 25: 368-373.

4 Garred P, Honore C, Ma YJ, Munthe-Fog L, Hummelshoj T. MBL2, FCN1, FCN2 and FCN3-The genes behind the initiation of the lectin pathway of complement. Mol Immunol 2009; 46: 2737-2744.

5 Henriksen ML, Brandt J, Andrieu JP, Nielsen C, Jensen PH, Holmskov U et al. Heteromeric complexes of native collectin kidney 1 and collectin liver 1 are found in the circulation with MASPs and activate the complement system. J Immunol 2013; 191: 6117-6127.

6 Axelgaard E, Jensen L, Dyrlund TF, Nielsen HJ, Enghild JJ, Thiel S et al. Investigations on collectin liver 1. J Biol Chem 2013; 288: 23407-23420.

7 Ma YJ, Skjoedt MO, Garred P. Collectin-11/MASP complex formation triggers activation of the lectin complement pathway-the fifth lectin pathway initiation complex. J Innate Immun 2013; 5: 242-250.

8 Garred P, Genster N, Pilely K, Bayarri-Olmos R, Rosbjerg A, Ma YJ et al. A journey through the lectin pathway of complement-MBL and beyond. Immunol Rev 2016; 274: 74-97.

9 Alcorlo M, Tortajada A, Rodriguez de Cordoba S, Llorca O. Structural basis for the stabilization of the complement alternative pathway C3 convertase by properdin. Proc Natl Acad Sci USA 2013; 110: 13504-13509.

10 van de Wetering JK, van Golde LM, Batenburg JJ. Collectins: players of the innate immune system. Eur J Biochem 2004; 271: 1229-1249.

11 Holmskov U, Jensenius JC. Structure and function of collectins: humoral C-type lectins with collagenous regions. Behring Inst Mitt 1993; 93: 224-235.

12 Sastry K, Ezekowitz RA. Collectins: pattern recognition molecules involved in first line host defense. Curr Opin Immunol 1993; 5: 59-66.

13 Hansen SW, Ohtani K, Roy N, Wakamiya N. The collectins CL-L1, CL-K1 and CL-P1, and their roles in complement and innate immunity. Immunobiology 2016; 221: 1058-1067.

14 Yongqing T, Drentin N, Duncan RC, Wijeyewickrema LC, Pike RN. Mannose-binding lectin serine proteases and associated proteins of the lectin pathway of complement: two genes, five proteins and many functions? Biochim Biophys Acta 2012; 1824: 253-262.

15 Han S, Mallampalli RK. The role of surfactant in lung disease and host defense against pulmonary infections. Ann Am Thorac Soc 2015; 12: 765-774.

16 Crouch E, Hartshorn K, Ofek I. Collectins and pulmonary innate immunity. Immunol Rev 2000; 173: 52-65.

17 Nakamura K, Funakoshi H, Miyamoto K, Tokunaga F, Nakamura T. Molecular cloning and functional characterization of a human scavenger receptor with C-type lectin (SRCL), a novel member of a scavenger receptor family. Biochem Biophys Res Commun 2001; 280: 1028-1035.

18 Ohtani K, Suzuki Y, Eda S, Kawai T, Kase T, Keshi H et al. The membrane-type collectin CL-P1 is a scavenger receptor on vascular endothelial cells. J Biol Chem 2001; 276: 44222-44228.

19 Jang S, Ohtani K, Fukuoh A, Yoshizaki T, Fukuda M, Motomura W et al. Scavenger receptor collectin placenta 1 (CL-P1) predominantly mediates zymosan phagocytosis by human vascular endothelial cells. J Biol Chem 2009; 284: 3956-3965.

20 Ma YJ, Hein E, Munthe-Fog L, Skjoedt MO, Bayarri-Olmos R, Romani L et al. Soluble collectin-12 (CL-12) is a pattern recognition molecule initiating complement activation via the alternative pathway. J Immunol 2015; 195: 3365-3373.
21 Endo Y, Matsushita M, Fujita T. Role of ficolin in innate immunity and its molecular basis. Immunobiology 2007; 212: 371-379.

22 Runza VL, Schwaeble W, Mannel DN. Ficolins: novel pattern recognition molecules of the innate immune response. Immunobiology 2008; 213: 297-306.

23 Munthe-Fog L, Hummelshoj T, Hansen BE, Koch C, Madsen HO, Skjodt K et al. The impact of FCN2 polymorphisms and haplotypes on the Ficolin-2 serum levels. Scand J Immunol 2007; 65: 383-392.

24 Munthe-Fog L, Hummelshoj T, Ma YJ, Hansen BE, Koch C, Madsen HO et al. Characterization of a polymorphism in the coding sequence of FCN3 resulting in a Ficolin-3 (Hakata antigen) deficiency state. Mol Immunol 2008; 45: 2660-2666.

25 Lu J, Tay PN, Kon OL, Reid KB. Human ficolin: cDNA cloning, demonstration of peripheral blood leucocytes as the major site of synthesis and assignment of the gene to chromosome 9. Biochem J 1996; 313: $473-478$.

26 Teh C, Le Y, Lee SH, Lu J. M-ficolin is expressed on monocytes and is a lectin binding to $\mathrm{N}$-acetyl-D-glucosamine and mediates monocyte adhesion and phagocytosis of Escherichia coli. Immunology 2000; 101: 225-232.

27 Liu Y, Endo Y, Iwaki D, Nakata M, Matsushita M, Wada I et al. Human M-ficolin is a secretory protein that activates the lectin complement pathway. J Immunol 2005; 175: 3150-3156.

28 Hummelshoj T, Fog LM, Madsen HO, Sim RB, Garred P. Comparative study of the human ficolins reveals unique features of Ficolin-3 (Hakata antigen). Mol Immunol 2008; 45: 1623-1632.

29 Endo Y, Matsushita M, Fujita T. New insights into the role of ficolins in the lectin pathway of innate immunity. Int Rev Cell Mol Biol 2015; 316: 49-110.

30 Garlanda C, Bottazzi B, Bastone A, Mantovani A. Pentraxins at the crossroads between innate immunity, inflammation, matrix deposition, and female fertility. Annu Rev Immunol 2005; 23: 337-366.

31 Mantovani A, Garlanda C, Doni A, Bottazzi B. Pentraxins in innate immunity: from C-reactive protein to the long pentraxin PTX3. J Clin Immunol 2008; 28: 1-13.

32 Bottazzi B, Doni A, Garlanda C, Mantovani A. An integrated view of humoral innate immunity: pentraxins as a paradigm. Annu Rev Immunol 2010; 28: 157-183.

33 Bottazzi B, Vouret-Craviari V, Bastone A, De Gioia L, Matteucci C, Peri G et al. Multimer formation and ligand recognition by the long pentraxin PTX3. Similarities and differences with the short pentraxins C-reactive protein and serum amyloid P component. J Biol Chem 1997; 272: 32817-32823.

34 Nauta AJ, Bottazzi B, Mantovani A, Salvatori G, Kishore U, Schwaeble WJ et al. Biochemical and functional characterization of the interaction between pentraxin 3 and C1q. Eur J Immunol 2003; 33: 465-473.

35 Baruah P, Dumitriu IE, Peri G, Russo V, Mantovani A, Manfredi AA et al. The tissue pentraxin PTX3 limits C1q-mediated complement activation and phagocytosis of apoptotic cells by dendritic cells. J Leukoc Biol 2006; 80: 87-95.

36 Nauta AJ, Daha MR, van Kooten C, Roos A. Recognition and clearance of apoptotic cells: a role for complement and pentraxins. Trends Immunol 2003; 24: 148-154.

37 Gershov D, Kim S, Brot N, Elkon KB. C-Reactive protein binds to apoptotic cells, protects the cells from assembly of the terminal complement components, and sustains an antiinflammatory innate immune response: implications for systemic autoimmunity. J Exp Med 2000; 192: 1353-1364.

38 Marchalonis JJ, Schluter SF. Immunoproteins in evolution. Dev Comp Immunol 1989; 13: 285-301.

39 Lu J, Marjon KD, Mold C, Du Clos TW, Sun PD. Pentraxins and FC receptors. Immunol Rev 2012; 250: 230-238.

40 Sierra R, Rello J, Bailen MA, Benitez E, Gordillo A, Leon C et al. C-reactive protein used as an early indicator of infection in patients with systemic inflammatory response syndrome. Intensive Care Med 2004; 30: 2038-2045.

41 Mold C, Nakayama S, Holzer TJ, Gewurz H, Du Clos TW. C-reactive protein is protective against Streptococcus pneumoniae infection in mice. J Exp Med 1981; 154: 1703-1708.

42 Szalai AJ, Briles DE, Volanakis JE. Human C-reactive protein is protective against fatal Streptococcus pneumoniae infection in transgenic mice. J Immunol 1995; 155: 2557-2563.

43 Szalai AJ, VanCott JL, McGhee JR, Volanakis JE, Benjamin WH Jr. Human C-reactive protein is protective against fatal Salmonella enterica serovar 
typhimurium infection in transgenic mice. Infect Immun 2000; 68: $5652-5656$.

44 Mold C, Rodgers CP, Kaplan RL, Gewurz H. Binding of human C-reactive protein to bacteria. Infect Immun 1982; 38: 392-395.

45 Suresh MV, Singh SK, Ferguson DA Jr, Agrawal A. Role of the property of C-reactive protein to activate the classical pathway of complement in protecting mice from pneumococcal infection. J Immunol 2006; 176 : 4369-4374.

$46 \mathrm{Ku} \mathrm{NO}$, Mortensen RF. The mouse C-reactive protein (CRP) gene is expressed in response to IL-1 but not IL-6. Cytokine 1993; 5: 319-326.

47 Ng PM, Jin Z, Tan SS, Ho B, Ding JL. C-reactive protein: a predominant LPS-binding acute phase protein responsive to Pseudomonas infection. $J$ Endotoxin Res 2004; 10: 163-174.

48 Iwanaga S, Lee BL. Recent advances in the innate immunity of invertebrate animals. J Biochem Mol Biol 2005; 38: 128-150.

49 Ng PM, Le Saux A, Lee CM, Tan NS, Lu J, Thiel S et al. C-reactive protein collaborates with plasma lectins to boost immune response against bacteria. EMBO J 2007; 26: 3431-3440.

50 Ma YG, Cho MY, Zhao M, Park JW, Matsushita M, Fujita T et al. Human mannose-binding lectin and L-ficolin function as specific pattern recognition proteins in the lectin activation pathway of complement. J Biol Chem 2004; 279: 25307-25312.

51 Soderhall K, Cerenius L. Role of the prophenoloxidase-activating system in invertebrate immunity. Curr Opin Immunol 1998; 10: 23-28.

52 Gillespie JP, Kanost MR, Trenczek T. Biological mediators of insect immunity. Annu Rev Entomol 1997; 42: 611-643.

53 Walport MJ. Complement. First of two parts. N Engl J Med 2001; 344: 1058-1066.

54 Yoshida H, Kinoshita K, Ashida M. Purification of a peptidoglycan recognition protein from hemolymph of the silkworm, Bombyx mori. $J$ Biol Chem 1996; 271: 13854-13860.

55 Kang D, Liu G, Lundstrom A, Gelius E, Steiner H. A peptidoglycan recognition protein in innate immunity conserved from insects to humans. Proc Natl Acad Sci USA 1998; 95: 10078-10082.

56 Ochiai M, Ashida M. A pattern recognition protein for peptidoglycan. Cloning the cDNA and the gene of the silkworm, Bombyx mori. J Biol Chem 1999; 274: 11854-11858.

57 Liu C, Xu Z, Gupta D, Dziarski R. Peptidoglycan recognition proteins: a novel family of four human innate immunity pattern recognition molecules. J Biol Chem 2001; 276: 34686-34694.

58 Shrive AK, Metcalfe AM, Cartwright JR, Greenhough TJ. C-reactive protein and SAP-like pentraxin are both present in Limulus polyphemus haemolymph: crystal structure of Limulus SAP. J Mol Biol 1999; 290: 997-1008.

59 Kairies N, Beisel HG, Fuentes-Prior P, Tsuda R, Muta T, Iwanaga S et al. The 2.0- A crystal structure of tachylectin $5 \mathrm{~A}$ provides evidence for the common origin of the innate immunity and the blood coagulation systems. Proc Natl Acad Sci USA 2001; 98: 13519-13524.

60 Holmskov U, Thiel S, Jensenius JC. Collections and ficolins: humoral lectins of the innate immune defense. Annu Rev Immunol 2003; 21: 547-578.

61 Fujita T, Matsushita M, Endo Y. The lectin-complement pathway-its role in innate immunity and evolution. Immunol Rev 2004; 198: 185-202.

62 Zhang J, Koh J, Lu J, Thiel S, Leong BS, Sethi S et al. Local inflammation induces complement crosstalk which amplifies the antimicrobial response. PLOS Pathog 2009; 5: e1000282.

63 Ma YJ, Doni A, Hummelshoj T, Honore C, Bastone A, Mantovani A et al. Synergy between ficolin-2 and pentraxin 3 boosts innate immune recognition and complement deposition. J Biol Chem 2009; 284: 28263-28275

64 Ma YJ, Doni A, Skjoedt MO, Honore C, Arendrup M, Mantovani A et al. Heterocomplexes of mannose-binding lectin and the pentraxins PTX3 or serum amyloid $\mathrm{P}$ component trigger cross-activation of the complement system. J Biol Chem 2011; 286: 3405-3417.

65 Garlanda C, Hirsch E, Bozza S, Salustri A, De Acetis M, Nota R et al. Non-redundant role of the long pentraxin PTX3 in anti-fungal innate immune response. Nature 2002; 420: 182-186.

66 Deban L, Jarva H, Lehtinen MJ, Bottazzi B, Bastone A, Doni A et al. Binding of the long pentraxin PTX3 to factor $\mathrm{H}$ : interacting domains and function in the regulation of complement activation. J Immunol 2008; 181: 8433-8440.

67 Braunschweig A, Jozsi M. Human pentraxin 3 binds to the complement regulator c4b-binding protein. PLOS ONE 2011; 6: e23991.
68 Csincsi Al, Kopp A, Zoldi M, Banlaki Z, Uzonyi B, Hebecker M et al. Factor H-related protein 5 interacts with pentraxin 3 and the extracellular matrix and modulates complement activation. J Immunol 2015; 194: 4963-4973.

69 Salustri A, Garlanda C, Hirsch E, De Acetis M, Maccagno A, Bottazzi B et al. PTX3 plays a key role in the organization of the cumulus oophorus extracellular matrix and in in vivo fertilization. Development 2004; 131: 1577-1586.

70 Rusnati M, Camozzi M, Moroni E, Bottazzi B, Peri G, Indraccolo S et al. Selective recognition of fibroblast growth factor-2 by the long pentraxin PTX3 inhibits angiogenesis. Blood 2004; 104: 92-99.

71 Doni A, Musso T, Morone D, Bastone A, Zambelli V, Sironi M et al. An acidic microenvironment sets the humoral pattern recognition molecule PTX3 in a tissue repair mode. J Exp Med 2015; 212: 905-925.

72 Daigo K, Yamaguchi N, Kawamura T, Matsubara K, Jiang S, Ohashi R et al. The proteomic profile of circulating pentraxin 3 (PTX3) complex in sepsis demonstrates the interaction with azurocidin 1 and other components of neutrophil extracellular traps. Mol Cell Proteomics 2012; 11: M111 015073.

73 Morgan J, Wannemuehler KA, Marr KA, Hadley S, Kontoyiannis DP, Walsh TJ et al. Incidence of invasive aspergillosis following hematopoietic stem cell and solid organ transplantation: interim results of a prospective multicenter surveillance program. Med Mycol 2005; 43(Suppl 1): S49-S58.

74 Hector RF, Yee E, Collins MS. Use of DBA/2 N mice in models of systemic candidiasis and pulmonary and systemic aspergillosis. Infect Immun 1990; 58: 1476-1478.

75 Rosbjerg A, Genster N, Pilely K, Skjoedt MO, Stahl GL, Garred P. Complementary roles of the classical and lectin complement pathways in the defense against Aspergillus fumigatus. Front Immunol 2016; 7: 473.

76 Svirshchevskaya EV, Shevchenko MA, Huet D, Femenia F, Latge JP, Boireau $\mathrm{P}$ et al. Susceptibility of mice to invasive aspergillosis correlates with delayed cell influx into the lungs. Int J Immunogenet 2009; 36: 289-299.

77 Henwick S, Hetherington SV, Patrick CC. Complement binding to Aspergillus conidia correlates with pathogenicity. J Lab Clin Med 1993; 122: 27-35.

78 Bidula S, Kenawy H, Ali YM, Sexton D, Schwaeble WJ, Schelenz S. Role of ficolin-A and lectin complement pathway in the innate defense against pathogenic Aspergillus species. Infect Immun 2013; 81: 1730-1740.

79 Bidula S, Sexton DW, Schelenz S. Serum opsonin ficolin-A enhances host-fungal interactions and modulates cytokine expression from human monocyte-derived macrophages and neutrophils following Aspergillus fumigatus challenge. Med Microbiol Immunol 2016; 205: 133-142.

80 Genster N, Praestekjaer Cramer E, Rosbjerg A, Pilely K, Cowland JB, Garred P. Ficolins promote fungal clearance in vivo and modulate the inflammatory cytokine response in host defense against Aspergillus fumigatus. J Innate Immun 2016; 8: 579-588.

81 Schelenz S, Kirchhof N, Bidula S, Wallis R, Sexton DW. Opsonizing properties of rat ficolin-A in the defence against Cryptococcus neoformans. Immunobiology 2013; 218: 477-483.

82 Bidula S, Sexton DW, Abdolrasouli A, Shah A, Reed A, Armstrong-James D et al. The serum opsonin L-ficolin is detected in lungs of human transplant recipients following fungal infections and modulates inflammation and killing of Aspergillus fumigatus. J Infect Dis 2015; 212: 234-246.

83 Martinez D, Vermeulen M, Trevani A, Ceballos A, Sabatte J, Gamberale R et al. Extracellular acidosis induces neutrophil activation by a mechanism dependent on activation of phosphatidylinositol 3-kinase/Akt and ERK pathways. J Immunol 2006; 176: 1163-1171.

84 Gaziano R, Bozza S, Bellocchio S, Perruccio K, Montagnoli C, Pitzurra L et al. Anti-Aspergillus fumigatus efficacy of pentraxin 3 alone and in combination with antifungals. Antimicrob Agents Chemother 2004; 48: 4414-4421.

85 Moalli F, Doni A, Deban L, Zelante T, Zagarella S, Bottazzi B et al. Role of complement and $\mathrm{Fc}$ \{gamma\} receptors in the protective activity of the long pentraxin PTX3 against Aspergillus fumigatus. Blood 2010; 116: 5170-5180.

86 Cunha C, Aversa F, Lacerda JF, Busca A, Kurzai O, Grube M et al. Genetic PTX3 deficiency and aspergillosis in stem-cell transplantation. $N$ Eng/ J Med 2014; 370: 421-432.

87 Rorvig S, Honore C, Larsson LI, Ohlsson S, Pedersen CC, Jacobsen LC et al. Ficolin-1 is present in a highly mobilizable subset of human 
neutrophil granules and associates with the cell surface after stimulation with fMLP. J Leukoc Biol 2009; 86: 1439-1449.

88 Tanio M, Wakamatsu K, Kohno T. Binding site of C-reactive protein on M-ficolin. Mol Immunol 2009; 47: 215-221.

89 Zhang J, Yang L, Ang Z, Yoong SL, Tran TT, Anand GS et al. Secreted $\mathrm{M}$-ficolin anchors onto monocyte transmembrane G protein-coupled receptor 43 and cross talks with plasma $\mathrm{C}$-reactive protein to mediate immune signaling and regulate host defense. J Immunol 2010; 185: 6899-6910.

90 Ma YJ, Doni A, Romani L, Jurgensen HJ, Behrendt N, Mantovani A et al. Ficolin-1-PTX3 complex formation promotes clearance of altered self-cells and modulates IL-8 production. J Immunol 2013; 191: 1324-1333.

91 Deban L, Jaillon S, Garlanda C, Bottazzi B, Mantovani A. Pentraxins in innate immunity: lessons from PTX3. Cell Tissue Res 2011; 343: 237-249.

92 Fearon DT, Austen KF. Properdin: binding to C3b and stabilization of the C3b-dependent C3 convertase. J Exp Med 1975; 142: 856-863.

93 Harboe M, Garred P, Lindstad JK, Pharo A, Muller F, Stahl GL et al. The role of properdin in zymosan- and Escherichia coli-induced complement activation. J Immunol 2012; 189: 2606-2613.

94 Agarwal S, Specht CA, Haibin H, Ostroff GR, Ram S, Rice PA et al. Linkage specificity and role of properdin in activation of the alternative complement pathway by fungal glycans. mBio 2011; 2: e00178-11.

95 Kemper C, Atkinson JP, Hourcade DE. Properdin: emerging roles of a pattern-recognition molecule. Annu Rev Immunol 2010; 28: 131-155.

96 Kemper C, Hourcade DE. Properdin: new roles in pattern recognition and target clearance. Mol Immunol 2008; 45: 4048-4056.

97 Roy N, Ohtani K, Matsuda Y, Mori K, Hwang I, Suzuki Y et al. Collectin CL-P1 utilizes C-reactive protein for complement activation. Biochim Biophys Acta 2016; 1860: 1118-1128.
98 Gout E, Moriscot C, Doni A, Dumestre-Perard C, Lacroix M, Perard J et al. $\mathrm{M}$-ficolin interacts with the long pentraxin PTX3: a novel case of cross-talk between soluble pattern-recognition molecules. J Immunol 2011; 186: 5815-5822.

99 Soares AC, Souza DG, Pinho V, Vieira AT, Nicoli JR, Cunha FQ et al. Dual function of the long pentraxin PTX3 in resistance against pulmonary infection with Klebsiella pneumoniae in transgenic mice. Microbes Infect 2006; 8: 1321-1329.

100 Gunn BM, Morrison TE, Whitmore AC, Blevins LK, Hueston L, Fraser RJ et al. Mannose binding lectin is required for alphavirus-induced arthritis/myositis. PLoS Pathog 2012; 8: e1002586.

101 Foo SS, Chen W, Taylor A, Sheng KC, Yu X, Teng TS et al. Role of pentraxin 3 in shaping arthritogenic alphaviral disease: from enhanced viral replication to immunomodulation. PLoS Pathog 2015; 11 : e1004649.

102 Foo SS, Reading PC, Jaillon S, Mantovani A, Mahalingam S. Pentraxins and collectins: friend or foe during pathogen invasion? Trends Microbiol 2015; 23: 799-811.

(c) (1) () $\Theta$ This work is licensed under a Creative Commons Attribution-NonCommercial-NoDerivs 4.0 International License. The images or other third party material in this article are included in the article's Creative Commons license, unless indicated otherwise in the credit line; if the material is not included under the Creative Commons license, users will need to obtain permission from the license holder to reproduce the material. To view a copy of this license, visit http://creativecommons.org/licenses/by-nc-nd/4.0/ 